\title{
PARÁFRASE DO MXG DO TRATADO DO NÃO-SER DE GÓRGIAS DE LEONTINOS
}

\author{
Apresentação e tradução por Aldo DINUCCI ${ }^{1}$
}

- RESUMO: Tradução a partir do grego clássico do Tratado do Não-Ser, de Górgias de Leontinos.

- PALAVRAS-CHAVE: Sofística, Ontologia, Górgias, Linguagem, Conhecimento.

\section{Apresentação do da Tradução da Paráfrase do MXG do Tratado do Não-Ser de Górgias de Leontinos}

O texto original do Tratado do Não-Ser não chegou até nós, mas sim duas paráfrases suas, uma na obra de Sexto Empírico e outra num pequeno tratado anexado à obra de Aristóteles, tratado este que sabemos hoje não ser da autoria do próprio Aristóteles. A paráfrase de Sexto aparece em sua obra Adversus Mathematicus (VII, 65 ss), a do Pseudo-Aristóteles no pequeno tratado Sobre Melisso, Xenófanes e Górgias (que chamaremos doravante de $M X G)$. Esta última é considerada como a melhor paráfrase por ser mais completa e precisa que aquela de Sexto, e é o objeto desta presente tradução.

A paráfrase de Sexto possui alguns inconvenientes: em primeiro lugar, foi composta sete séculos após a morte de Górgias; em segundo lugar, possui toda uma elaboração que é em si mesma estranha a Górgias, como a colocação do problema ao início do Tratado (VII, 65 ss), certas formalizações lógicas e todo um vocabulário próprio à Escola Cética (Cassin: 1995, p.121-2). A paráfrase de Sexto foi a mais transmitida (é a única colocada entre os fragmentos

1 É Doutor em Filosofia pela Pontifícia Universidade Católica do Rio de Janeiro, PUC-RJ e professor adjunto da Universidade Federal de Sergipe. Artigo recebido em 03/08 e aprovado em 06/08. 
de Górgias por Diels-Kranz, por exemplo), e esta foi provavelmente a razão principal de se considerar Górgias como um cético.

A paráfrase do $M X G$ é anterior à de Sexto, mas não sabemos ao certo quem a escreveu nem quando: alguns manuscritos antigos afirmam ser obra do próprio Aristóteles (hipótese hoje descartada), outros manuscritos afirmam ser da autoria de Teofrasto (Cassin: 1995, p.121-2); Diels (p.148-9) afirma ser obra de um peripatético do século três a.C.; Untersteiner (1993, p.149) crê ser obra proveniente da Escola de Mégara. Apesar de não sabermos quem é seu autor, o $M X G$ reconhecidamente contém a melhor paráfrase do Tratado, muito embora esteja corrompido em alguns trechos.

As recentes investigações de Kahn e seus seguidores sobre o uso do verbo ser no grego clássico nos levam a uma outra interpretação da expressão célebre que abre o Tratado: Ouk einai phesin ouden (MXG, 979 a, 1-5). O verbo ser (aqui no infinitivo presente) era comumente traduzido por existir, e a frase recebia então como tradução "[Górgias] diz que nenhuma coisa existe". Tal afirmação era então tomada como uma ironia de Górgias, e o Tratado considerado como um "jogo" onde Górgias procura ironizar sistematicamente a posição de Parmênides.

Entretanto, Kerferd, desenvolvendo a interpretação de Kahn acerca da significação do verbo ser em grego, ${ }^{2}$ chega à conclusão de que os filósofos gregos preocupavam-se especialmente como problemas de predicação, que eles "tendiam antes a considerar mais como problemas de inferência de qualidades e características de objetos no mundo real à nossa volta". 3 Assim, o dito de Górgias seria melhor traduzido do seguinte modo: "[Górgias] diz que nenhuma coisa é". Colocada desta forma, a frase não soa mais como uma colocação absurda, mas como a afirmação de que nada é em sentido estrito, ou melhor, a afirmação de que coisa nenhuma possui as características próprias à concepção parmenídica do ser: nada é eterno, incriado, uno, imutável, etc.

O Tratado do Não-Ser é particularmente importante para a compreensão da célebre defesa do princípio de não de Aristóteles, no livro IV, da Metafísica, onde o estagirita tem em vista justamente contornar as objeções levantadas por Górgias em relação à consistência da noção de ser e os problemas daí decorrentes no âmbito da teoria do conhecimento e da linguagem.

2 Segundo a qual tanto o uso existencial como o predicativo do verbo ser se remetiam a um uso mais fundamental, mais próximo do predicativo que do existencial (cf. Kerferd: 1994, p.94 ss.)

3 Kerferd: 1994, p.95 (A filosofia grega até o século IV a.C., ao falar do ser, não considerava o conceito de existência como separado do conceito de ser. Tal distinção só foi realizada posteriormente). 


\section{Paráfrase pseudo-aristotélica do Tratado do Não-Ser de GÓRGIAS no $M X G$}

[Górgias] diz que nenhuma coisa é: se é, é incognoscível: se tanto é quanto [é] cognoscível, não é, no entanto, [comunicável] a outros. E conclui que não é, reunindo (15) as coisas ditas por uns e outros, isto é, todos os que, dizendo coisas contrárias acerca do-que-é, denunciam-se - como parece - uns aos outros. Alguns, por um lado, mostrando que [é] um e não múltiplas coisas, outros, por outro lado, ao contrário, que [é] múltiplas coisas e não um, e alguns mostrando que elas não são geradas, outros mostrando-as como geradas. Ele conclui aquilo de acordo com ambos os lados, pois [é] necessário, diz [Górgias], que, se alguma coisa é, <é ou bem um ou bem múltiplas coisas e ou bem não-geradas ou bem geradas. Se então > não ocorre ser (20) nem um nem múltiplas coisas, nem não-geradas nem geradas, coisa alguma seria. Pois, se alguma coisa fosse, seria uma ou outra destas coisas. Que, <então,> não é nem um nem múltiplas coisas, nem não-geradas nem geradas, por um lado como Melisso, por outro como Zenão, [Górgias] tentar mostrar depois de sua própria primeira demonstração, na qual diz (25) que nem ser nem não-ser é. Se, com efeito, o não-ser é não-ser, o-que-não-é em nada seria menos que o-que-é. Pois, tanto o-que-não-é é algo-que-não-é, quanto o-que-é [é] algo-que-é, de modo que as coisas em nada mais são do que não são. Se, no entanto, o não-ser é, (30) o ser, a sua antítese, não é, diz ele. Se, com efeito, o não-ser é, convém ao ser não ser. De modo que, assim, diz [Górgias], não seria coisa alguma, a menos que tanto o ser quanto o não-ser sejam a mesma coisa. Mas, se [são] a mesma coisa, também assim coisa nenhuma seria. Pois tanto o-que-não-é não é quanto o-que-é [não é], já que, justamente, [é] o mesmo que o-que-não-é. Eis aí, então, o argumento dele. Mas de parte alguma resulta, a partir daquilo que [Górgias] tem dito, que coisa nenhuma (35) é. Pois, mesmo o que eles demonstram, assim é pensado?. Se o-que-não-é é, ou é pura e simplesmente ou da maneira como o-que-não-é também é algo-que-não-é. Mas, isto nem se mostra assim nem é necessário. Mas, supondo que duas coisas fossem, por um lado, o-que-é, por outro, o-que-parece, o primeiro é, o segundo não (979 b) [é] verdadeiro, porque é o-que-não-é. Porque razão, com efeito, nem ser nem não-ser são? Ambos - e não um ou outro - são. Pois o-quenão-é - diz ele - em nada seria menos que o-que-é, (5) se é que também oque-não-é fosse algo, quando todos afirmam que o-que-não-é de modo algum é. Se também o-que-não-é é algo-que-não-é, o-que-não-é não seria, assim, de modo semelhante ao-que-é. Pois o primeiro é algo-que-não-é e o segundo ainda assim é. E mesmo se fosse pura e simplesmente verdadeiro, quão espantoso, na verdade, seria: "o-que-não-é é". Mas, se fosse assim, 
qual das duas coisas resulta de melhor modo: "todas as coisas são" ou "todas as coisas não são"? Pois, deste modo, o próprio oposto parece surgir. Com efeito, se tanto o-que-não-é é algo-que-é quanto o-que-é é algo-que-é, tudo é. Pois tanto as coisas-que-são quanto as coisas-que-não-são são. Pois não é necessário, se algo-que-não-é é, que algo-que-é não seja. Se, mesmo deste modo, alguém concedesse que, por um lado, o-que-não-é fosse, e, por outro, que o-que-é não fosse, no entanto, nada menos seria algo, pois, de acordo com o argumento dele, as coisas-que-não-são seriam. No entanto, se o não-ser e o ser são o mesmo, nem assim algo não seria mais do que seria. Pois, como também (15) ele [Górgias] diz, se o-que-é e o-que-não-é são o mesmo, tanto o-que-é quanto o-que-não-é são, de modo que coisa nenhuma é. Pelo argumento contrário poder-se-ia dizer que tudo é. Pois tanto oque-não-é quanto o-que-é são, (20) de modo que todas as coisas são. Depois de seu argumento, [Górgias] diz que, se [algo] é, é, em verdade, ou não-gerado ou gerado. Se [é] não-gerado, concede, pelas teses de Melisso, que é infinito: no entanto, o infinito não poderia ser em parte alguma. Pois nem seria em si próprio nem em outro. Pois, deste modo, haveria dois infinitos, tanto aquele-que-é-em quanto aquele-no-qual-é (25) de acordo com o argumento de Zenão acerca do espaço, coisa nenhuma seria em parte alguma. Então, devido a disto, não é não-gerado nem gerado. Portanto, nada seria gerado nem a partir do-que-é nem a partir do-que-não-é. Pois, se fosse gerado a partir do-que-é, se transformaria, o que é impossível, pois, se o-queé se transformasse, não mais seria algo que é propriamente, (30) do mesmo modo que, se também o-que-não-é fosse gerado, não mais seria algo-quenão-é. Nem certamente seria gerado a partir do-que-é. Se, com efeito, o-quenão-é não é, coisa alguma poderia ser gerada a partir do nada. No entanto, se o-que-não-é é a partir do-que-não-é, não é gerado a partir do-que-é, em razão das quais devido às quais precisamente tampouco é gerado a partir do-que-é. (35) Se, então, é necessário que se algo é, é, em verdade, não-gerado ou gerado, e isto é impossível, é impossível também que algo seja. Ademais, se algo é, é ou um ou mais numerosos, diz [Górgias]: no entanto, se não [é] nem um nem múltiplas coisas, coisa alguma seria. E - diz ele certamente um não seria, porque o um seria verdadeiramente incorpóreo, na medida em que não possui nenhuma grandeza, o que é refutado pelo argumento de Zenão. Mas, se não é um, nada seria absolutamente. (980 a) Pois, não sendo um, também não pode ser múltiplas coisas. Mas, se não é nem é um nem múltiplas coisas, diz [Górgias], coisa nenhuma é. E, também, coisa nenhuma se moveria. Pois, movendo-se, não possuiria mais a mesma forma, mas, por um lado, o-que-é seria o-que-não-é, e, por outro, o o-quenão-é viria a ser, ademais, se perfizesse o movimento, pelo que se deslocaria, (5) não sendo contínuo, seria dividido, mas, onde é dividido, o-que-é não 
está no lugar em que é dividido. De modo que, movendo-se todas as partes, por todas as partes é dividido. No entanto, sendo assim, não é em parte alguma. Pois falta ser aí onde é dividido, diz [Górgias], e chama isto de dividido ao invés de vazio, do mesmo modo que está escrito nos argumentos creditados a Leucipo. Então, diz que estas são as demonstrações de que nada é: depois destas mesmas demonstrações, [Górgias] diz que, se é, é incognoscível. Com efeito, é necessário que todas as coisas pensadas sejam, (10) e o-que-não-é, já que não é, não pode ser pensado. No entanto, sendo assim, ninguém diria nada falso, diz [Górgias], nem mesmo se diz que carros de guerra combatem no mar. Pois, neste caso, todas as coisas seriam. E, com efeito, por causa disto, as coisas vistas e as coisas ouvidas serão, porque cada uma delas é pensada. Mas, (15) se não é assim, e, do mesmo modo que as coisas que vemos, em nada mais são porque as vemos, assim as coisas que vemos não mais são pensadas porque as vemos, (e, com efeito, do mesmo modo que tanto muitos aí vêem estas coisas quanto muitos estas coisas pensassem), porque, portanto, seria mais evidente que tal coisa é? Mas não é evidente que tipo de coisas é verdadeiro. De modo que, se tais coisas também são, para nós seriam incognoscíveis. E, com efeito, se são cognoscíveis, como, diz [Górgias], poderia alguém (20) comunicá-las a outro? Pois, diz, como poderia alguém comunicar a outro, pela palavra, aquilo que vê? Ou como poderia alguma coisa ser evidente (980 b) para alguém que a escute e não a veja? Pois, do mesmo modo que a visão não conhece os sons, assim a audição não ouve as cores, mas os sons: e aquele que diz diz, mas não a cor nem a coisa. Portanto, como poderia alguém, não tendo determinada coisa no espírito, vir a tê-la no espírito por intermédio de outra pessoa, através da palavra ou do signo, que é diferente (5) da coisa, a não ser que ou, por um lado, veja-a, se for uma cor, ou, por outro, escute-a, se for um som? Pois, a princípio, ninguém diz nem o som nem a cor, mas a palavra. De modo que não é possível pensar a cor mas vê-la, também não é possível pensar o som mas ouvi-lo. Se, no entanto, também é admissível tanto conhecer quanto ler a palavra, como o que escuta terá no espírito a mesma coisa? Pois (10) não é possível o mesmo estar simultaneamente em numerosas pessoas, pois um seria dois. Se, no entanto, diz [Górgias], o mesmo também fosse em muitas pessoas, nada impede que não pareça semelhante para eles, já que, não sendo, nem são semelhantes para todos nem [estão] no mesmo lugar: pois, se algo fosse de tal qualidade, seria um, mas não dois. No entanto, nem (15) um mesmo homem parece perceber coisas semelhantes ao mesmo tempo, mas coisas diferentes pela audição e pela visão, e diferentemente tanto agora quanto antes, de modo que dificilmente alguém perceberia uma mesma coisa idêntica a uma outra. Assim, nada é; se é algo, é tanto porque as coisas não são as palavras quanto porque ninguém (20) 
tem no espírito a mesma coisa que outra pessoa. Todos os filósofos, incluindo este [Górgias], consideram os problemas dos filósofos mais antigos, de modo que, na investigação acerca daqueles [Górgias e outros], também será preciso examinar a fundo os problemas dos filósofos mais antigos.

Agradecimento: Ao Professor Fernando Rodrigues do IFCS/UFRJ.

- ABSTRACT: Translation from classic greek of Gorgias Leontini's Treatise of NotBeing.

- KEYWORDS: Sophistic, ontology, Gorgias, language, knowledge.

\section{Referências bibliográficas}

AUBENQUE. Le Problème de L'être chez Aristote. 2.ed. Paris: Quadrige, 1994.

BARBOSA \& CASTRO. Górgias: Testemunhos e Fragmentos. Lisboa: Colibri, 1993.

BETT. "The Sophistis and Relativism" in Phronesis, 34 (1989) p.139-69.

CASSIN. L'Effect Sophistique. Paris: Gallimard, 1995.

DIELS-KRANZ. Die Fragmente der Vorsokratiker. 6.ed. Berlim, 1952.

DINUCCI, Aldo. O Estatuto Lógico, Lingüístico e Ontológico da defesa de Aristóteles do Princípio de Não-Contradição contra Górgias e Antístenes no Capítulo IV do Livro da Metafísica. Dissertação de mestrado não publicada aprovada com louvor pela PUC-RJ.

DUPRÉEL. Les Sophistes Protágoras, Górgias, Hippias. Neuchatel: Griffon, 1948.

GOMPERZ, H. Sophistic und Rethoric. Leipzig, 1912.

GUTHRIE, W. K. C. History of Philosophy. Vol 3. Cambridge: Cambridge University Press, 1969.

IJSSELING, Samuel. "Rhétorique et Philosophie" in La Revue Philosophique de Louvain, n.22, 1976, p.210.

ISÓCRATES. Discourses. Trad. La Rue Van Hook. Londres: Harvard University Press, 1964.

KAHN, Charles. "The Verb 'to be' and the Concept of Being" in Foundations of language ${ }_{2}$ 2, 1966.

KERFERD, G. B. The Sophistic Moviment. 2.ed. Cambridge: Cambridge University Press, 1984.

KIRK-RAVEN. Os Filósfos Pré-Socráticos. 4.ed. Trad. Carlos Alberto Louro Fonseca. Lisboa: Calouste Gulbenkian, 1994.

LEVI, A. "Studi su Gorgia" in Logos, XIV, 1941, p.38ss.

MAURA IGLESIAS. "Platão, a Descoberta da Alma" in Informativo SBEC, n.23, 1999. QUINTILIANO. Institutio Oratoria. Trad. H. E. Butler. Londres: Harvard University Press, 1923. 
RENAHAN. "Polo, Plato and Aristotle" in Classical Quarterly, 45, 1995, p.68-72.

SEXTO EMPÍRICO. Complete Works. Trad. R. G. Bury. 4.ed. Londres: Harvard University Press, 1987.

UNTERSTEINER. Les Sohistes. Vol. 1. Trad. Alonso Tordesillas. Paris: Vrin, 1993, p.214-26.

WOLFF, Francis. "Les Trois Langage-mondes" in La Liberté de L'Esprit. Hachete, Paris, março de 1996. 